and aggressive immunosuppressive therapy. Nevertheless, therapy for TM in the context remains insufficient and should be assessed in a controlled clinical trial setting. REFERENCES:

[1] Monahan RC, et al. Mortality in patients with systemic lupus erythematosus and neuropsychiatric involvement: A retrospective analysis from a tertiary referral center in the Netherlands. Lupus. 2020 Dec;29(14):1892-901.

[2] Papachristos DA, et al. Management of inflammatory neurologic and psychiatric manifestations of systemic lupus erythematosus: A systematic review. Semin Arthritis Rheum. 2020 Dec 17;51(1):49-71.

Disclosure of Interests: PETER KORSTEN Consultant of: PK has received honoraria by Abbvie, Bristol-Myers-Squibb, Chugai, Gilead, Glaxo Smith Kline, Janssen-Cilag, Pfizer, and Sanofi-Aventis, all unrelated to this study., Grant/ research support from: PK has received research grants from GSK, unrelated to this study., Marlene Plüß: None declared, Stefanie Glaubitz: None declared, Ala Jambus: None declared, Radovan Vasko: None declared, Bettina Meike Göricke: None declared, Silvia Piantoni: None declared

DOI: 10.1136/annrheumdis-2021-eular.1210

\section{AB0284 COMBINATION THERAPY WITH RITUXIMAB AND BELIMUMAB IN PATIENTS WITH SYSTEMIC LUPUS ERYTHEMATOSUS}

A. Mesnyankina ${ }^{1}$, E. Aseeva ${ }^{1}$, N. Nikishina ${ }^{1}$, A. Torgashina ${ }^{1} .{ }^{1}$ V.A. Nasonova Research Institute of Rheumatology, Federal State Budgetary Scientific Institution, Moscow, Russian Federation

Objectives: To assess the efficacy of combined therapy with rituximab (RTM) and belimumab (BLM) in patients with active systemic lupus erythematosus (SLE). Methods: The study included 12 SLE pts $(1 \mathrm{M} / 11 \mathrm{~F})$ with severe (SLEDAI2K $\geq 10$ - 8pts.) and moderate (SLEDAI2K<10- 4pts.) disease activity; out of them 5 patients had lupus nephritis, vasculitis and 7 had predominantly mucocutaneous and articular manifestations of SLE. The dose of oral GC was: $60 \mathrm{mg}$ in one patient with vasculitis, LN, cerebrovasculitis; in 9 patients from 10 to $5 \mathrm{mg}$; in 2 patients without oral glucocorticoids. All patients with SLE with kidney damage, CNS, and vasculitis received cytostatics. All patients with vasculitis, LN, etc. received mycophenolate mofetil or cyclophosphamide. Rituximab (RTM) was administered at 500-2000 mg, with subsequent adding of Belimumab (BLM) 1-6 months later at a standard dosing regimen $10 \mathrm{mg} / \mathrm{kg}$ once a month a total of 7 infusions. The following parameters were evaluated: the effectiveness of therapy, the concentration of autoantibodies, the dose of oral corticosteroids initially at the time of RTM administration and then every 3 months after the initiation of BLM therapy.

Results: 8 pts demonstrated the decrease in clinical and laboratory SLE activity, starting from $3 \mathrm{mo}$ of follow-up. After the start of BLM infusions, a decrease in SLE activity was observed in all patients. Among them, 9 had SLEDAI-2K activity of less than 4 points (SLEDAI-2k Me 12 [9,5;17], after treatment of RTM and BLM 4[2;4]). Only one patient (№4) had a relapse of SLE, due to the omission of the BLM infusion. He was receiving standard GC doses. In dynamics, a decrease anti-double DNA titres (Me $101[39 ; 250] \mathrm{U} / \mathrm{ml}$ vs $19[9 ; 70] \mathrm{U} / \mathrm{ml})$, C3 $(0,44[0,39 ; 0,59] \mathrm{g} / \mathrm{l}$ vs $0,81[0,72 ; 0,87] \mathrm{g} / \mathrm{l}), \mathrm{C} 4(0,06[0,031 ; 0,1] \mathrm{g} / \mathrm{l}$ vs $0,14[0,13 ; 0,14] \mathrm{g} / \mathrm{l})$ was registered. The GC dose was reduced in most patients (tab. 1), but the previously prescribed immunosuppressive therapy continued. There were no cases of severe infection. Conclusion: Combination therapy allows to gain control over disease activity in short time, due to the effect of RTM, while added BLM provides further prolongation of the effect achieved, minimizing the risk of flare. The use of such therapy contributes to a rapid and effective reduction in the activity of the disease, normalization of laboratory markers of SLE (at to ds-DNA, C3, C4), the use of lower doses of oral GCs. This combination may be used as a method of choice in pts with severe SLE involving vital organs, and in persistent cutaneous-articular disease and high immunological activity.

Table 1. Dose of oral glucocorticoids (prednisone), mg

\begin{tabular}{lcccc}
\hline No patient & $\begin{array}{c}\text { Before the introduction of } \\
\text { RTM, mg }\end{array}$ & $\begin{array}{c}\text { 1st 7th injection of of } \\
\text { BLM, mg }\end{array}$ & $\begin{array}{c}\text { 7th injection of } \\
\text { BLM, mg }\end{array}$ & \\
\hline 1 & 20 & 20 & 15 & $\downarrow$ \\
2 & 7,5 & 5 & 5 & $\downarrow$ \\
3 & 5 & 5 & 5 & $=$ \\
4 & 10 & 10 & 10 & $\downarrow$ \\
5 & 5 & 5 & 5 & $=$ \\
6 & 60 & 7,5 & 2,5 & $\downarrow \downarrow$ \\
7 & 10 & 2,5 & 0 & $\downarrow \downarrow$ \\
8 & 10 & 10 & 5 & $\downarrow$ \\
9 & 2,5 & 10 & 2,5 & $=$ \\
10 & 10 & 0 & 5 & $\downarrow$ \\
11 & 0 & 0 & 0 & $=$ \\
12 & 0 & & & $=$ \\
\hline
\end{tabular}

Disclosure of Interests: None declared DOI: 10.1136/annrheumdis-2021-eular.1499

\section{\begin{tabular}{|l|l}
\hline AB0285 EFFECTIVENESS OF IMMUNOSUPPRESSIVE \\
\hline
\end{tabular} THERAPY FOR CONNECTIVE TISSUE DISEASE-ASSOCIATED PULMONARY ARTERIAL HYPERTENSION}

R. Kishikawa ${ }^{1}$, M. Hatano ${ }^{1,2}$, S. Ishii ${ }^{1}$, M. Shimbo ${ }^{1}$, A. Saito ${ }^{1}$, S. Minatsuki ${ }^{1}$ Y. Iwasaki ${ }^{3}$, K. Fujio ${ }^{3}$, I. Komuro'. ' ${ }^{1}$ Graduate School of Medicine, The University of Tokyo, Department of Cardiovascular Medicine, Tokyo, Japan; ${ }^{2}$ Graduate School of Medicine, The University of Tokyo., Department of Therapeutic Strategy for Heart Failure, Tokyo, Japan; ${ }^{3}$ Graduate School of Medicine, The University of Tokyo, Department of Allergy and Rheumatology, Tokyo, Japan

Background: Connective tissue disease (CTD) associated pulmonary arterial hypertension (PAH) is considered to be an indication for immunosuppressive therapy (IT) except scleroderma associated PAH. However, the response rate defined by improvement of WHO functional class and hemodynamic parameters is reported to be around $50 \%$ [1]. Since CTDs are systemic diseases, it may be difficult to evaluate the efficacy of IT by subjective symptoms. Although there are previous studies reporting that the combined use of IT and pulmonary vasodilators significantly improved hemodynamics [2], response to IT without titration of pulmonary vasodilators remains to be elucidated.

Objectives: To examine whether IT is effective for CTD-PAH.

Methods: We retrospectively examined the medical records of consecutive 13 patients with CTD-PAH (female 13, mean age $47 \pm 15$ years) treated with methylprednisolone $(1 \mathrm{mg} / \mathrm{kg} / \mathrm{day}$, oral) and intravenous bolus cyclophosphamide (IVCY) $\left(500 \mathrm{mg} / \mathrm{m}^{2}\right)$ every four weeks for six times. Patient characteristics are described in Table 1. Right heart catheterization (RHC) was done at prior to IT, before adding PAH specific agents, and at the fifth or sixth course of IVCY. In treated cases, the previous vasodilators remained unchanged during the first term of IT.

Results: At the first follow up $\mathrm{RHC}$, decrease of mean pulmonary arterial pressure over $5 \mathrm{mmHg}$ was observed in all patients, and decrease of pulmonary vascular resistance (PVR) was observed in twelve out of 13 patients (Figure 1). Over $20 \%$ of PVR reduction was observed more in the patients of pulmonary vasodilator naïve and started IT within one year from symptoms than others $(6 / 7$ vs $1 / 6, p=0.03)$ Although six-minutes walk distance (6MWD) tended to be prolonged between first and second RHC (298 $\pm 70 \mathrm{~m}$ vs $382 \pm 81 \mathrm{~m} ; \mathrm{p}=0.054 ; \mathrm{n}=9), 6 \mathrm{MWD}$ was shortened in some cases with good hemodynamic improvement (2/5). All patients were prescribed oral $\mathrm{PAH}$ specific agents finally, but no one needed parenteral pros tanoids. Two patients (15\%) died during maintenance therapy for causes other than $\mathrm{PAH}$. Three-year and five-year survival rates were $91.7 \%$ and $81.5 \%$, respectively. Conclusion: IT without titration of pulmonary vasodilators significantly improved hemodynamic parameters despite of less improvement in 6MWD in CTD-PAH patients. Considering that CTDs itself might affect the exercise tolerance regardless of $\mathrm{PAH}$, these hemodynamic changes may contribute to better prognosis and IT might be considered especially for patients early in clinical courses and treatment naïve.

\section{REFERENCES:}

[1] Jais X, Launay D, Yaici A, et al. Immunosupressive therapy in lupus-and mixed connective tissue disease-associated pulmonary arterial hypertension. ARTHRITIS RHEUM. 2008; 58(2): 521-531.

[2] Yamamoto M S, Fukumoto Y, Sugimura K, et al. Intensive immunosuppressive therapy improves pulmonary hemodynamics and long-term prognosis in patients with pulmonary arterial hypertension associated with connective tissue diseasae. Circ J. 2011; 75: 2668-2674.

Table 1. Characteristics of patients

\begin{tabular}{lccccc}
\hline Patient & $\begin{array}{c}\text { Age, } \\
\text { yr }\end{array}$ & $\begin{array}{c}\text { Connective } \\
\text { Tissue Disease }\end{array}$ & $\begin{array}{c}\text { Years from symptom } \\
\text { to immunosuppressive } \\
\text { therapy }\end{array}$ & $\begin{array}{c}\text { Previous } \\
\text { vasodilators }\end{array}$ & $\begin{array}{c}\text { vasodilators at } \\
\text { final visit }\end{array}$ \\
\hline 1 & 47 & SS & 1.5 & PGI2 & ERA \\
2 & 62 & SS, RA & 2 & none & PDE5 \\
3 & 32 & SS & 1 & none & ERA \\
4 & 57 & SS, SSc & 0.5 & none & PDE5 \\
5 & 26 & SS,MCTD, & 0.5 & none & PDE5 \\
& & SLE,SSc & & sGC, ERA & sGC, ERA \\
6 & 70 & SSc, SS s/o & 13 & none & PDE5 \\
7 & 32 & SS S/O, SLE & 0.1 & ERA,PDE5, PGI2 & ERA,PDE5, PGI2 \\
8 & 31 & MCTD & 3 & ERA, PDE5 & ERA,PDE5, PGI2 \\
9 & 43 & SSc, SLE & 0.6 & none & nGC \\
10 & 67 & MCTD,PM & 0 & none & ERA, PDE5 \\
11 & 41 & SS & 0.1 & PDE5 \\
12 & 69 & SS & 0.3 & none & ERA, SGC \\
13 & 44 & SS, MCTD s/o, & 0.1 & &
\end{tabular}

N.A, not acquired; s/o, suspect of; SS, Sjögren's syndrome; RA, rheumatoid arthritis; SSc systemic sclerosis; SLE, systemic lupus erythematosus; MCTD, mixed connective tissue disease; PM, Polymyositis; PGI2, prostacyclin derivative; SGC, soluble guanylate cyclase stimulator ERA, endothelin receptor antagonist; PDE5, phosphodiesterase type 5 inhibitor. 